\title{
Females Voices through the Lens of Feminism and Critical Race Theory
}

\author{
Sharada Neupane Lohani ${ }^{2 *}$, Suresh Lohani ${ }^{1}$ \\ ${ }^{I}$ Two master's degrees in English from Pokhara University \\ ${ }^{2}$ Graduate student in the Department of Education at the University of Texas at EL Paso
}

*Corresponding Author: Sharada Neupane Lohani, Graduate student in the Department of Education at the University of Texas at EL Paso

\begin{abstract}
Power relations between genders are often murky though most often when talking about power dynamics between males and females, it is by default assumed that women are treated with bias by patriarchy. Women in most cases are the victims of rape and other kinds of mental and physical abuses by males. However, there are social, educational and gender issues that also victimize men as they are forced to take up the stereotypical roles that the society assigns them. This paper talks about certain texts of varied genres that deal with the power issue between genders and how, despite being presented as emotionally and physically vulnerable characters, female characters have revolted and talked back to the oppression of patriarchy. Similarly, there are certain male characters that are portrayed inferior to female characters, thus challenging the perceived power dynamics between genders that is at play. The authors, using the lens of feminism and critical race theory, talk about how it would be unfair to go for a sweeping generalization that it is only the women that are the victims in this power play, and also suggest some changes in educational system, such as adopting multimodal pedagogical strategies, to help the ones on the margin regain their voice and resist the suppression imposed on them.
\end{abstract}

Keywords: Power, Discrimination, Stereotype, Gender

Power is shifting in nature and does not have one particular determinant. In fact, society, culture, religion and spatio-temporal locations profoundly affect power balance between the genders. In most of the cases, the differential equation of power manifests through stereotypical roles, internalized by both, its holders and pursuers. Yet in other instances, the ones assuming various responsible positions, with conformity to power balance, in a tacit way are engaged in the process of empowering themselves, most often at the cost of stripping off the other party's equal share to it. It would, with due consideration to fluctuating socio-cultural patterns, thus be unfair to go with a sweeping generalization that men blatantly exercise their power by unjustly inflicting suffering onto women; for in trying to do so, they themselves are entrapped in the much yearned discourse of male chauvinism. In the texts that will be discussed below, we shall look at various scenarios of power play conditioned by economic status, education, politics, regional situatedness and cultural identity. Ashok Bhusal (2017), in his "Emphasizing the Suppression of Feminist Voices," investigates "the suppression tactics used to marginalize or ignore four women rhetoricians from the prior four centuries, including seventeenth-century English writer Mary Astell, eighteenth-century English author Mary Wollstonecraft, the nineteenth-century American writer Margaret Fuller, and the later nineteenth and early twentieth-century African American writer Ida Bell Wells" (p. 14). It means there are many tools employed to suppress their voices in our society. Therefore, it is our responsibility as a citizen to speak for marginalized voices. Next, Suresh Lohani (2019) in "Constructing Nontraditional Rhetoric: Critical Study on Gloria Anzaldua and Suresh Canagarajah" talks about how language is purposefully used to maintain the status quo. He states "whether it is the males dominating the females or the believers of heterosexual normativity looking down upon the peoples of different gender orientations, there is a constant tension between the practitioners of homogeneity and diversity" (p.118). Thus, female voices have been silenced by dominant forces under different pretexts and the resistance from the women's side so far has not proved to be effective enough.

In Rape by Wanda Coleman, insensibility of man is fore grounded through the perpetration of rape committed onto a woman by various males from different walks of life. The poem is probably a 
sweeping generalization that all men are alike and that they are barbaric at heart, devoid of any human attributes. Males may take up different roles of father, son, husband or any other professional but the commonality they all share is their supremacy they want to see prevail over women under different pretexts. The very policemen, for instance, who were supposed to come to the rescue of the woman resort to enacting the same heinous act onto the victim. In this case, the uniform of the police they are wearing perhaps "empowers" them to derive sexual gratification out of a woman who is already so brutally treated. The doctor, likewise, in place of eliciting objective information seeks sexually charged details for he wants "every detail", "next detail" and "detail, detail" (p.154). Her boyfriend too fares no better with her emotions as in place of comforting her emotionally he indifferently asks "why didn't she call the police" (p. 154). Ironically he who should have empathized with her suffering, tacitly holds her, in some way, responsible for what happened and the height of brutality is reached when "he pulled down his pants, forced her back onto the sheets" (154) and fulfilled his libido. The other burglars too have their way with hermercilessly and provide her with a fake solace: "when you get lonely, call" (p. 155). In all the instances, the perpetrators are male and the victim is female. These men have clearly abused their authority, emotional bonding and physical strength in a bid to subdue a member of the opposite sex. However, what can be inferred in the poem is that even the victim is not just a passive receiver of the crime, but obviously an exhibitor of power for she kills the policemen who make a mockery of her misery. In a short span of time a paradigm shift in power equation is witnessed and the clout of patriarchy was crumbled. It nonetheless can be sensed as a poem embedded with radical feminist elements and propelled with a mission of demonizing the entire male species. On a critical note, a dispassionate reader will probably be appalled by the stench of fundamental feminism entailed in the poem where men are portrayed as cannibals who ruthlessly devour the other sex of the same species. There are ample fabrications and generalizations in the poem to make it a one sided story.

In She Being Brand by E.E. Cummings a comparison has been made between a locomotive and a woman. The operation system of a car is shown to be analogous with sexual activities and the expressions "how nice she acted right up to the last minute" (p. 157) and "her radiators made sure her springs were O" (p. 156) have erotic overtures. So, the poem is largely centered around commodifying women and presenting them as inanimate objects that merely cater to the comfort and pleasure of patriarchy. Likewise, in The Applicant by Sylvia Plath both male and female genders have been ridiculed. The desire of the men and women to restructure themselves and fit the perfect model of masculinity and femininity has been materialized through the use of "a glass eye, false teeth or a crutch" (p. 159) and "Rubber breasts or a rubber crotch" (p. 159). This could be one example of how these offerings of technology are gradually stripping both men and women off their natural charisma and "relegating" both the sexes to the female gender. Now even artificial objects can act as substitutes to human anatomical features and it is literally possible to employ them in attaining human needs. So this is an illustration of how even the advancement of science is involved in engendering gender roles leading to considerable reduction in already enjoyed stereotypical masculine and feminine roles.

In yet another poem DanseRusse by William Carlos Williams, there is an elaboration of entrapment of gender roles and what appears on the surface may be strikingly different from the reality underneath. To elucidate further, it can be seen in the poem that the male member in the family seeks odd hour of the night coupled with solitude of his room to enjoy the real freedom of life; otherwise he is forced to take up the role of a responsible macho man. The writer says, “... I admire my arms, my face, my shoulders...drawn shades" (p. 161). This shows how suffocated is the man within the institution of family comprising his wife and the baby. These members in the family, as can be inferred in the poem, had rather compelled the man to act against his true self and thus clipped from him the joy of freedom .However, upon the arrival of the opportune moment, the man unleashing his storm of liberation would "dance naked, grotesquely" (p. 161).The poem is a subtle mutiny of genuine human emotions against socially constructed gender roles, largely by a patriarchal design. However, what is interesting to note here is that the patriarchal mission of weakening the females oftentimes boomerangs the male chauvinism itself. Thus, who is powerful here, the woman enjoying a sound sleep or the man waiting for a quiet moment to appreciate his "authentic masculinity" is a contested issue.

Moving on to Sanda Cisneros'Eyes of Zapata, there is an oscillating transfer of power between man and woman. In the first place, the lead male character is portrayed as a politically influential and handsome figure. This man is a lady killer and any girl would literally resign to his manly charms. However, it is also interesting to note that this man falls for the narrator thus tacitly endorsing the 
defeat of masculinity to female fragility. The woman does dare to defy the wish of her father in the hope uniting with the man of her dreams forever, and this is not just the power of love but a direct challenge from a young girl to a rigid patriarchal structure. Another case in a point here is how the narrator's father and the narrator's lover are like arch rivals as according to the narrator her father ruled out any possibility of conciliation and she mentions "not even on his death bed did he forgive you" (p. 166). This is a proof that the battle for power is not only fought between the genders but even within the same gender the tussle continues: the more powerful is portrayed as masculine and the defeated one as feminine. The narrator is yet to acquire the status of a wife and that adds to her powerlessness implying that a woman acquires differential power influence in the capacity of wife, lover or whore as she says to him, "What is it I am to you? Sometime wife? Lover? Whore...To be one is not so terrible as being all" (p. 173). Further on, the narrator in her soliloquy says, "You always come back. In between and the others. That's my magic. You come back to me" (p. 170). This is a clear example of how again despite the power, pelf and mobility, men do not really entail that vigor which reflects on their personality. They may be quick and impulsive but women may be forgiving and have a greater degree of perseverance which at some point help them exert control over men. In the story, the male lead establishes relationships with many other women and attempts to prove his superiority and this is responded by the narrator thus: "You have your pastimes...... You have left many mothers crying" (p. 170). The narrator strongly discards this attitude and further states "Ay! Your eyes. Eyes with teeth" (p. 171). This is an effort to demonize men and show how uncaring and irresponsibly tormenting they can be, even to the woman they once loved, upon finding other beautiful women as they move along. Even someone so charismatic people like Miliano, the lead male character, has certain feminine approaches in his mannerism for the narrator refers to him by saying "Your voice Milano, thin and light as a woman's" (p. 174).So concealed within a gruff exteriorirrespective of one's sex- one may still embody a softer tone and gesture which neither of the sexes in fact can claim to be their sole acquisition. There are many other instances in the story where the power dynamics keep shifting not just between the genders but within the genders as well. In addition, the political standing of Miliano also affects his power relations.

In Alice Walker's Porn, it can be seen that when education background and income of females and males are on the same level, the power status is also at equilibrium, whether it is in the case of separation or commencing of a new relationship. The man and woman both being divorcees meet and engage in a sexual relationship and thoroughly enjoy each other's company. However, the man still has wildest sexual fantasies and through his collection of the porn he wants the woman to "be turned on by it too!" (p. 190). This is where the male wants to take the woman beyond the confines of emotional attachment and use her as a tool to fulfilling his deepest sexual fantasy; this may not be the desire of the lady. And indeed because of this proposal the lady's mind drifts elsewhere and her participation in the act of copulation is devoid of real enthusiasm. So even when it comes to sexual intercourse men have an edge over women. In The High Heeled Shoes: A Memoir the case is that men want to harass women in all possible ways and in so doing they do not care about morality in the least. One of such harrowing cases is the one where "a man came from behind and grabbed her, stopped her mouth with his ...between kiss and rape" (p. 196). On account of, perhaps, their physical strength males oftentimes overpower women and perform the most "cowardice act." And yet another encounter of the narrator was with a man wearing women's clothes and exposing his penis and deriving sexual pleasure out of the act of exhibitionism. Even in this story allusions have been made about how all men unknowingly or on purpose-that includes even Mahatma Gandhi-hold views that can be interpreted as anti-feminist.

In the movie The Hot Chick, it can be seen that sex really is a biological attribute and that gender is a social construct. The level of energy and enthusiasm if not conditioned by patriarchy and its agencies remains the same, both in males and females. Another scene is that of gender demarcation within the same sex. This is apparently visible both in the circle of girls where some girls with "ugly" physique are made fun of and even boys are mocked by other boys for being too loyal to their girls and thus inclined towards embracing a feminine identity. In How our body shapes our minds, a talk show, power is emanated to some extent through non-verbal communication and stretching of the limbs indirectly is associated with power and confidence. Both males and females could be either stretching their limbs or shrinking their posture and thus exhibiting whether they are powerful ones or weaker ones. However, even in this case, girls seem more diffident than boys as the girls "with hands on their necks were more insecure and less confident." The suggestion put forth by Ammy Cuddy, the 
presenter is that body language has direct connections with the mind and vice-versa and that to start with, one should "start faking till you not just make it but become it", meaning that even if it does not really come from your inner self, you should still pretend to be stretched out and thus confident till you really achieve it through internalization. Indeed, "body language affects how others see us, but it may also change how we see ourselves. Social psychologist Amy Cuddy shows how "power posing" standing in a posture of confidence, even when we don't feel confident - can affect testosterone and cortisol levels in the brain, and might even have an impact on our chances for success."

The other talk show, Killing Us Softly, talks about the dangers that many advertisements pose by trying to create "perfect males" and "perfect females." These advertisements are totally bent on creating archetypal male and female models by injecting into people's psyche that only people of certain vital statistics, and attired in a certain manner, have the power and confidence and that others devoid of these fall farther from the margin of perfection. Most of the advertisements have used and exploited women by setting certain standards for them to conform to and the failure on their part to do so convert them to abject humans. This has compelled many female models and others alike suffer from malnutrition in a bid to stay slim and ultimately succumb to anorexia. However, it has not spared the males either, and in the days to come it can be predicted their suffering will be on a par with the women's. For example, even young boys are presented like "macho" adults and that muscular body of theirs coupled with harsh mannerisms would make them ideal male figures. Thus, even the business stunts performed by the corporate world have shaped different identities for both the sexes and this could further complicate the status quo of the sexes in the days to come. Feminism is concerned with the status of women in our society. A feminist and multimodal scholar, Ashok Bhusal (2017) in his "Emphasizing the suppression of feminist voices" states that we need to "look for other women rhetors who have been largely marginalized or ignored and reclaim their contributions in the twentyfirst century" (p. 56). Critical race theory is also similar to feminism in that the former provides a framework for combating any discriminatory activities aimed against minorities. While feminism is concerned with the status of women in society, critical race theory is concerned with minority racial groups. Ashok Bhusal (2017) in his "The rhetoric of racism and anti-miscegenation laws in the United States" says that it is important that we "complete a deeper study of minorities and bring their stories, their voices, into academic scholarship" (p. 88). He suggests some ways as effective practices such as "using personal (counter) narratives, increasing exposure to multicultural education, and incorporating the study of all minorities in critical race theory" (p. 88). No matter which minority group a person belongs, all of them should come together to fight against racist practices in our society.

The textbooks used for classroom purposes are key to educating people about race, culture, and gender. These days, multimodal textbooks are getting popular, but it is important that we carefully include multiple modes in these texts. Ashok Bhusal (2019), in his "Addressing FYC instructors' lack of technological expertise in implementing multimodal assignments," defines multimodality as "multiple modes of communication -- textual, aural, visual, and spatial" (p. 167). With the advent of technological innovations, it is important that we use multimodality in the textbooks in a way that all minorities are presented with respect and care. Ashok Bhusal's idea aptly connects to Suresh Lohani's (2016) take on multimodality that it helps dismantle the clout of the dominant language that is bent on, in tacit or overt ways, promoting the interests of the dominant class. In "The history of multimodal composition, its implementation, and challenges, "he states that "multimodality, speaking from the translingual perspective, is a challenge to autonomous orientation to literacy that advocates for the conformation to the dominant language conventions" (p.123). Although Lohani is looking at multimodality though translingual lens, it equally fits male-female power contexts since females too are the placed on the margin by patriarchy and the blanket model education-the same one for both genders- they receive basically supports the patriarchal supremacy.

In another article titled "The rhetoric of racism in society," Ashok Bhusal (2019) presents how racist practices of whites "have caused many problems for the marginalized. [The minorities] question their own identity and put down their own traditions to acquiesce to the majority" (p. 114). Therefore, as Bhusal in his "The rhetoric of racism and anti-miscegenation laws in the United States" states "What is necessary at this point is, with the tools offered in critical race theory, is to complete a deeper study of minorities and bring their stories, their voices, into academic scholarship" (p. 88). This version alludes to what Suresh Lohani (2016) says in "LGBTI in Nepal, Pakistan, and India: Law, Religion, and Individuals." Lohani explores the issues of LGBTI minorities in the South Asian context and talks about how society and law in general treat them unfavorably. He states that "in societal level, it can be 
seen that the very social fabric is not conducive towards acceptance of LGBTI. As a result, many people of alternative gender-sexual orientations are forced to color their very identity with heterosexuality" (p.41). Patriarchal mindset places LGBTI people in the same basket where females are kept and the discriminations and harassments they undergo are similar to the ones experienced by females.

To sum up, various cultural, corporal, economic and social factors, to name a few have immensely contributed to power dynamics in the society. Although patriarchy still falls heavy on the female gender, a lot of cracks in the middle have begun to emerge. These fractures have shaken traditional power balances and in fact created overlaps in the power equations today leading to gradual rejection of stereotypical role performance. And in the days to come significant alterations and developments could be witnessed in the gendered domains and today's status quo would be dismantled altogether.

\section{REFERENCES}

[1] Bhusal, A. (2017). Emphasizing the suppression of feminist voices. International Journal of Humanities and Cultural Studies (IJHCS) 4(2), 53-57.

[2] Bhusal, A. (2019). Addressing FYC instructors' lack of technological expertise in implementing multimodal assignments. In Marginalia in Modern Learning Contexts (pp. 166-186). IGI Global.

[3] Bhusal, A. (2017). The rhetoric of racism and anti-miscegenation laws in the United States. IAFOR Journal of Arts \& Humanities, 4(2), 83-89.

[4] Bhusal, A. (2019). The Rhetoric of Racism in Society. Journal of Research Innovation. 9(1), 111-114.

[5] Leitch, Vincent B. General Editor. The Norton Anthology of Theory and Criticism. New York: Norton, 2001.

[6] Wiegman, R. and Elena G. Literature and Gender: Thinking Critically Through Fiction, Poetry and Drama. New York: Longman, 1999.

[7] Cuddy,Ammy. "How Our Body Shapes Our Minds."YouTube. October 1, 2012.Web.13 May 2013.

[8] Killbourne, J. (2012). “Killing Us Softly.”YouTube. May 21, 2009.Web.5 May 2013.

[9] The Hot Chick.Tom Brady.Touchstone Pictures, Film.

[10] Lohani, S. 2016. " LGBTI in NEPAL, Pakistan, and India: Law, Religion, and Individuals ." MPhil Thesis, Department of English, Pokhara University, Nepal.

[11] Lohani, S. (2019). Constructing Nontraditional Rhetoric: Critical Study on Gloria Anzaldua and Suresh Canagarajah. Journal of Research Innovation 9 (1).

[12] Lohani, S. (2019). The History of Multimodal Composition, Its Implementation, and Challenges. The Criterion: An International Journal in English10 (1).

\section{AUTHORS' BIOGRAPHY}

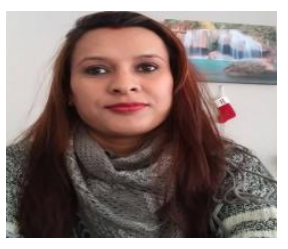

Sharada Lohani is a graduate student in the department of Education at UTEP. Her research interests include feminism, critical race theory, and social justice.

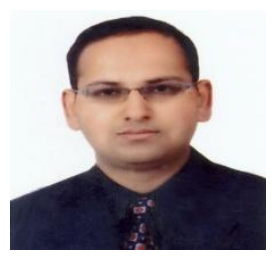

Suresh Lohani is an active researcher. He has taught English courses for two decades at the university level in Nepal. His research interests focus on feminism, critical race theory and multimodal composition.

Citation: Sharada Neupane Lohani, Suresh Lohani. Females Voices through the Lens of Feminism and Critical Race Theory. "International Journal on Studies in English Language and Literature (IJSELL), vol 7 , no. 9, 2019, pp. 62-66. doi: http://dx.doi.org/10.20431/2347-3134.0709005.

Copyright: () 2019 Authors. This is an open-access article distributed under the terms of the Creative Commons Attribution License, which permits unrestricted use, distribution, and reproduction in any medium, provided the original author and source are credited. 